\title{
A summer reading
}

\section{programme}

RACHEL CROMIE, INGRID GWILLIAM FA'ALOGO, MARILYN GWILLIAM, AND LIBBY LIMBRICK

\section{KEY POINTS}

- This collaborative project was a school and community response to research on the effects of the summer break on reading achievement.

- $\quad$ The project was located in a local setting between the school and the public library.

- The project included students, their whānau, school staff, library staff, and the local community board.

- The outcomes indicated the importance of focused literacy teaching and learning, relationships, and effective communication. 
Current national and international research indicates the summer break can negatively affect students' reading achievement. To counter this effect, our primary school with a range of students worked in collaboration with our local public library to plan and implement a summer reading programme. The purpose of the programme was to increase students' reading engagement with the aim of improving reading achievement levels. This article describes the project and its outcomes.

\section{The "summer slide" and what we aimed to do about it?}

New Zealand and international research about the summer effect on reading achievement has been reported widely by McNaughton, Jesson, and Kolose (2012), Alexander, Entwhistle, and Olson (2007), and Allington and McGill-Franzen (2010). These studies refer to the documented drop in reading achievement for many students over the long summer breaks, ${ }^{1}$ particularly those from low-income families. One explanation for the summer effect is that children from poorer families are more likely to have limited access to paper-based and digital reading material over the summer break (Allington, McGill-Franzen, Camilli, Williams, Graff, Zeig et al. 2007, cited in McNaughton et al., 2012). Cumulative low achievement, therefore, is not surprising as high levels of engagement in reading are widely, and consistently, demonstrated as predictive of ongoing literacy achievement (e.g., Cunningham \& Stanovich, 1991).

Papatoetoe Central School, a large decile 4 contributing school located in a suburb south of Auckland, set out to investigate whether a summer reading programme (SRP) would assist in improving students' reading levels and attitudes to reading. In response to the literature and our own school community we developed and implemented an SRP during the 2014/2015 summer holiday. We wanted to tailor the SRP to reflect the interests, backgrounds, and experiences of our students and their whānau. The students came from a variety of ethnic backgrounds: 9\% Māori, 14\% Pasifika, 51\% Indian, and $18 \%$ Chinese with the remainder European New Zealanders. Only 26\% spoke English as their first language at home.

We had an existing relationship with our local Papatoetoe library and we planned to develop this further by working with the library staff in the development and implementation of the SRP. We believed that by locating the SRP in the library during the summer break, our students would benefit from its resources and the literary environment. We involved the local community board so that in the future they might consider funding the initiative.

At the same time we intended to examine our instructional practices in literacy teaching such as guided reading, comprehension, and discussion strategies in preparation for the SRP. We wanted to integrate the project into our ongoing review of school-wide reading programmes. In effect our teachers were engaged in school-based teacher professional learning in preparation for the 2014/2015 SRP, which led to new approaches in classroom reading programmes as well the actual library-based programme. We were intent on evaluating what worked and what didn't work in the development and implementation of the SRP, especially in relation to the so-called "summer slide".

\section{Research design to develop and evaluate the SRP}

The school's entire Year 5 cohort took part in the project. Previous achievement data had indicated some concern about a number of students' reading levels, especially in the area of comprehension at the end of Year 4. Year 5 was chosen also as it is the year before students enter their last year in primary school, and just before intermediate school when attitudes to reading have been shown to drop markedly (Flockton \& Crooks, 2000; Crooks \& Flockton, 2004; Crooks, Smith, \& Flockton, 2008). That is, we wanted increase students' engagement in reading before Year 6 , their final year at our school.

The research involved a mixed-method design (Creswell, 2009): qualitative data were gathered to inform the development of an SRP and to evaluate the programme, and quantitative data were collected to meaure reading achievement and attitudes to reading. 
The participants included the Year 5 teaching team, a research-support teacher, the principal, the library staff, 115 students and their whānau, and a researcher. The Year 5 teaching team leader regularly shared project updates and findings with the school's reading development team, and we all considered the emerging findings in relation to the teaching of reading for the research cohort and across the school.

Data used to inform the development of the SRP were gathered from four student focus groups, two whānau groups, and a focus group of all the Year 5 teachers plus a research-support teacher. Qualitative data ${ }^{2}$ were also gathered the following year (in early 2015) to evaluate the SRP through informal observations of the programme in action, focus groups with students and teachers, a survey of parents and caregivers whose children attended the programme, and interviews with librarians, the reading support teacher, the principal, and the local community board representative. (See Figure 1 for detail about the qualitative evaluative data).

Students' attitudes to reading were measured using the NEMP (National Education Monitoring Project) Attitude to Reading Survey during the year prior to the SRP as the 2014 Year 5 cohort, and following the SRP in Term 12015 as the Year 6 cohort. NEMP Attitude to Reading Surveys provided quantitative measures of students' enjoyment of reading, self-confidence, selfefficacy in reading, and feelings about libraries.

Reading achievement data (STAR-Supplementary Tests of Achievement in Reading) (Elley, 2003) for the Year 5 cohort were accessed from the school assessment database (e-Tap SMS) for reading achievement at the usual times scheduled for assessment: the end of year 2013 (as Year 4 students); beginning of year 2014 and end of year 2014 (as Year 5 students); and beginning of year 2015 (as Year 6 students). STAR reports on word recognition, vocabulary, sentence comprehension, and paragraph comprehension. Data were entered in SPSS and analysed for, first, the entire cohort, and secondly, for students who were high attenders of the SRP during the long summer holidays.

\section{Collaborative relationships helped us build towards the SRP}

From the outset, the team of four teachers participating in this research understood the project to be an evolving, collaborative, and holistic approach to reading. Throughout the year, library staff, school staff and the researcher met to develop the SRP by sharing ideas to inform their classroom practice and ultimately develop a 4-week summer programme of reading-related activities. Staff at the Papatoetoe library helped to formulate the major aims of the 2014/2015 SRP, which were to develop and nurture a partnership with the library, and to promote and continue reading over the summer holiday for our students. As early as Term 1 in 2014 the school team and the Papatoetoe library team began to look at how a SRP might complement the local library's Dare to Explore annual summer programme. Dare to Explore, an Auckland-wide generic holiday programme, provides reading-related challenges for primary school students in a number of libraries. Indeed, the Papatoetoe SRP came to be built on Dare to Explore by extending content and structure so to align more closely with the emerging needs and expressed interests of the Papatoetoe School students. The library team provided us with the space and assistance from their staff to help us implement the programme.

The views of parents, caregivers, and students were also solicited to discover and acknowledge their interests and needs in order to ensure their "ownership" of the SRP. We drafted two possible programmes as we were surprised at the large number of suggestions we had been given by all participants, the students in particular. The selected programme was less dependent on digital technology than we had expected, thus minimising the implications of bringing and managing students' own devices in the library. This SRP plan was shared with the library staff, and they felt it complemented Dare to Explore and was manageable in the library context.

Thus the project's co-constructive nature-from planning to implementation and reflection-was evident at each phase. At the back of our minds, as teachers, was an understanding that the SRP should not be merely an extension of the school's instructional reading programme, but rather an opportunity to explore books in a relaxed setting.

\section{Our classroom programme led up to the SRP}

From its very inception, the project shone a spotlight on reading at school and made us as a team consider a number of questions more carefully. What did it actually mean to be a reader? How could the project ensure that every student in the cohort succeeded in reading? And how, as a team, could we inspire a lifelong love of reading? The aim was not to see the SRP as an isolated 4 weeks of extra reading during the summer holidays, but as one component of a larger ongoing and developing reading programme.

The first step was to examine strategies that could potentially raise the profile of reading across the year group. We knew it would be impossible to require students to attend the summer component of the project, so the "lead in" year was developed to motivate 
attendance. Arising from collaborative team brainstorms, a variety of approaches and activities were adopted throughout 2014.

One strategy included the involvement of the aforementioned research-support teacher, one day per week, to supplement and enhance the existing reading programme. This time was used throughout the year to support and extend all ability levels. The support took the form of a 45-minute guided reading session with an emphasis on using literature. The support teacher taught six groups every Thursday with target groups being reviewed each term. All students below and at expected achievement levels were in targeted groups. Middleability and high-ability groups were also identified for acceleration work each term. In addition, the researchsupport teacher worked with groups of new Englishlanguage learners to help them engage more confidently with the classroom programme. The focus of the support teacher's sessions was on understanding extended texts at a deeper level which included developing vocabulary knowledge, identifying the main idea and supporting evidence, and critical responses to texts. This became known as the literacy enhancement zone. Additionally, it allowed the research-support teacher to build strong relationships with the Year 5 students, as well as becoming familiar with their reading interests and achievement levels. This established strong foundations for the 2014/2015 SRP that the research-support teacher would lead in the library.

Other classroom approaches included:

- each term, Year 5 -specific reading newsletters were sent to parents

- big e-books and audio stories were used comprehensively

- student reading diaries were introduced

- bookmarks were designed and created for the school's market day

- classes visited the local library

- each term, year-groups listened to teacher read-alouds of a novel

- associated presentations were given at fortnightly team assemblies.

The idea of teacher read-alouds of a novel had been suggested by a member of the project's reference group. A key objective of read-alouds is to inspire in children a love of literature. It has been described as a tool for motivating students to read (Rog, 2001), and according to Anderson, Hiebert, Scott, and Wilkinson (1985) "the single most important activity for building the knowledge required for eventual success in reading is reading aloud to children" (p. 33).

The teaching team evaluated a range of novels and then presented three of these to the Year 5 students. This was followed by a student-evaluation exercise aimed at developing student ownership. Although daily readalouds had been an established practice in the school, year-group read-alouds was a new approach. We felt that to give the students a level of autonomy and choice would be more likely to lead to a successful outcome. Students then voted for the novel they most wanted to hear. Enthusiasm rose markedly. The selected novel, which was read to each of the Year 5 classes, often became a topic of excited discussion in the playground during morning and lunch breaks.

\section{The SRP took place in the local library}

The library-based SRP took place across 4 weeks during January 2015. Every day of the week the research-support teacher and a teacher aide set up the resources for the day's activities (such as special books, paper, and drawing and construction materials) in the children's section of the library. They met all the students there who, after a greeting and briefing, were free to find a place in that same area or the teen section upstairs.

Attendance each day ranged from eight to nineteen students; 41 students (just under 50\% of the Year 5 cohort) attended one or more sessions. Eleven of them attended more than $50 \%$ of the sessions. They arrived

\section{Although daily read-alouds had been an established practice in the school, year- group read-alouds was a new approach. We felt that to give the students a level of autonomy and choice would be more likely to lead to a successful outcome. Students then voted for the novel they most wanted to hear. Enthusiasm rose markedly. The selected novel, which was read to each of the Year 5 classes, often became a topic of excited discussion in the playground during morning and lunch breaks.}


at the library on bikes or on foot, or were driven by parents or caregivers. A few Papatoetoe Central School students invited friends and family from other schools, and some of these children came back with their friend after attending their first session with us. Children from the community visiting the library with their families or friends would frequently ask what we were doing and many toddlers picked up a crayon and started drawing alongside us. This sense of community was apparent throughout the duration of the SRP, reinforced by the programme activities that we planned and facilitated.

We had planned that each day would begin with a personal reading time. In that first week we realised that this would need a purpose so that reading took precedence over simply chatting with friends. From then on the research-support teacher and teacher aide circulated around asking the students questions about book characters, setting, and themes. Sometimes, the librarian would share new titles or read to the group. This was particularly valuable for encouraging the students to branch out and try different genres and authors. One week she talked to the students about using the computer to locate a title or subject area for research or personal purposes.

Each week students participated in one or two activities, some more-strongly related to what they were reading than others.

The library staff had booked a 3D printer from the city library and invited our group to experiment with it as most of the students had not encountered one previously. Published author and Papatoetoe resident Jack Gabolinscy came along and spoke with the students, sharing his ideas and work. A marvellous storyteller, $\mathrm{Mr}$ Gabolinscy answered many questions from our curious participants. Alongside these visitors and machines were simple activities involving pen, crayons, and poster paper, such as book "selling" posters and visual storyboards for books they had read. These proved popular, allowing our summer readers to interact with one another about what they had been reading and what they considered to be highlights.

In our planning we hadn't included a celebration on the final day, but as the SRP came to a close we felt it would be welcomed by the students. We wanted to recognise the participation and support that they had given to the SRP. We encouraged the students to dress up as their favourite book character and enjoy a shared morning tea together at the library. A more formal recognition and prizegiving assembly was held early in February 2015, back at school.

It was the people who made this project special: the students, their teachers and whānau, the project's leadership, the research-support teacher, and the library staff. The adults worked together, talked together and with the children, and co-constructed a SRP that provided students with a place to go to read, chat, and reflect with their peers in a relaxed community setting.

\begin{abstract}
Student focus groups explored what they enjoyed, or did not enjoy, what they felt they had gained from the SRP, their advice for teachers and librarians planning another SRP, and what they would say to a friend or family member who had a chance to attend a programme like the SRP. A group of highattending students also presented a summary of their thoughts about the SRP to their cohort.

Year $\mathbf{5}$ teachers discussed four areas: student outcomes; impact on teachers; relationships between the school and the library; and their views on the sustainability of future SRPs.

The parents and caregivers survey asked about their children's responses to the SRP and their views on what the programme had achieved.

Interviews with the librarians and the research-support teacher elicited views in five areas. These included the perception of their roles; personal satisfactions; strengths and challenges that arose; their perceptions of the students' responses to the programme, and suggestions for future SRPS.
\end{abstract}

FIGURE 1. QUALITATIVE EVALUATIVE DATA

\section{Outcomes of the SRP}

\section{Student achievement}

The STAR data revealed a notable improvement for the whole Year 5 cohort after the 2014/2015 summer holiday break in comparison with the previous year (Table 1). The cohort mean overall stanine score for STAR dropped only 1.2 stanines, whereas after the 2013/2014 summer break it had dropped 2.0 stanines. Furthermore the sentence and paragraph comprehension data showed not a loss but an increase in the stanine scores.

TABLE 1. COHORT DIFFERENCES IN MEAN SCORES

OVERALL IN SUMMER PERIODS 2013/ 2014 AND

2014/ 2015 (STAR TEST)

\begin{tabular}{|l|c|c|c|c|c|}
\hline & Cohort & Stanine & Vocabulary & $\begin{array}{c}\text { Sentence } \\
\text { Comp }\end{array}$ & $\begin{array}{c}\text { Para } \\
\text { Comp }\end{array}$ \\
\hline $2013 / 2014$ & Difference & $-\mathbf{2 . 0}$ & $\mathbf{+ 1 . 7}$ & $-\mathbf{0 . 4}$ & $\mathbf{- 3 . 1}$ \\
\hline $2014 / 2015$ & Difference & $-\mathbf{1 . 2}$ & $\mathbf{+ 0 . 3}$ & $\mathbf{+ 0 . 5}$ & $\mathbf{+ 1 . 3}$ \\
\hline
\end{tabular}

It is notable that these apparent improvements in reading achievement are for the whole cohort, not only for those who had attended the project's summer component. STAR data collected at the beginning of 2015 also indicated a smaller summer slide occurred for the students who had high attendance (that is attended for more than $50 \%$ of the session) at the summer holiday programme than for the same students in previous years. The difference, however, is not as marked as for the whole cohort (Table 2) 
TABLE 2. DIFFERENCES IN HIGH ATTENDERS' MEAN SCORES IN SUMMER PERIODS 2013/ 2014 AND 2014/ $2015(n=13)$

\begin{tabular}{|l|c|c|c|c|c|}
\hline & $\begin{array}{c}\text { High } \\
\text { Attenders }\end{array}$ & $\begin{array}{c}\text { Overall } \\
\text { Stanine }\end{array}$ & Vocabulary & $\begin{array}{c}\text { Sentence } \\
\text { Comp }\end{array}$ & $\begin{array}{c}\text { Para } \\
\text { Comp }\end{array}$ \\
\hline $2013 / 2014$ & Difference & -1.9 & +2.6 & -0.4 & -1.8 \\
\hline $2014 / 2015$ & Difference & -1.2 & +0.5 & +0.4 & -0.3 \\
\hline
\end{tabular}

The Year 6 teachers commented that they had also observed a growth in vocabulary, higher levels of critical thinking, and improved comprehension-particularly the depth of understanding in terms of more difficult story plots and characters - for the entire Year 5 cohort when engaged in classroom reading.

\section{Student attitudes}

The Year 5 students' data from NEMP in 2014 had suggested they already had positive attitudes to reading. Thus it is not surprising that, when assessed in 2015, there appears to have been little change.

There is one exception. The data suggest that the students who had been high attenders had greater selfefficacy in reading and identified as readers more strongly after the summer holidays in 2015 than in 2014. When asked "How do you feel about how you read?" 11 out the 12 students recorded a smiley face compared with only six of the twelve after the summer holidays in the previous year. It has not been possible to establish whether this would constitute a significant difference because of the small sample size.

Teachers also commented that their students were more motivated and enthusiastic towards reading, and had observed greater engagement with extended texts. Overall they said there was marked improvement in students' confidence in, and view of themselves as readers. Many students, too, said they thought they had become better readers as a result of being part of the project.

\section{Teaching and learning as inquiry}

Many of the approaches that were trialled with the Year 5 students in 2014 were exploratory in nature. The year-group teacher read-aloud identified a range of social, interactive, and collaborative possibilities around the act of reading. These possibilities raised several questions for the teaching team about the impact of their own pedagogical approaches. Student motivation and enthusiasm appeared to have hugely increased over the course of 2014 as a direct result of the ongoing novel readalouds. The teachers undertook an informal survey which confirmed this observation. Students said that the cohortwide novel had created a shared experience. They said:
"Because we all talk about the story, we understand it better."

"We end up talking about our own problems and dilemmas."

"We exchange opinions and ideas and see things from different points of view."

The outcomes of this aspect of the project have also led to ongoing teacher inquiry and team-based professional learning for all the members of the teaching team. Early 2015 saw the introduction of pilot weekly post read-aloud discussion circles, giving students dedicated time and opportunity to discuss literature in greater depth. In 2015 the same group of students who had participated in the research, now Year 6, read five novels together.

Certainly the SRP had a sustainable influence on teacher practice. Teachers were more aware of the importance of student discussion about what they were reading. The classes had become a community of readers, and teachers were committed to growing and nourishing rich conversations about the books they were reading.

\section{What did we learn from this inquiry?}

This project has convinced us that a summer slide in reading achievement can be minimised, and even prevented. It adds to an increasing body of national and international research suggesting that such slippage is not inevitable in low socioeconomic contexts (e.g., Kim \& Quin, 2013; Meyer, Meissel, \& McNaughton 2015; Turner \& Tse, 2015). We have learnt however, that a reading programme during the summer break alone may be insufficient to raise student reading achievement.

Other factors, in addition to the SRP itself, appear to have contributed to the students' improved performance in this project. Students have benefited from the "total package", with the most powerful component being the teachers' awareness of their own roles in enhancing student engagement and motivation. They also became more aware of the importance of monitoring the impact of their teaching strategies and of adjusting and adapting their practice accordingly. It became clear that teacher knowledge and commitment is pivotal to minimising the potentially negative impact of long holiday breaks on student reading achievement.

This project has also confirmed that the development of a community of readers, in which reading is a base of social interaction, such as the cohort-wide read-aloud, fosters student engagement and discussion about books which can impact positively on student achievement. As Krashen (2004) stated in an overview of the research on the effects of reading aloud, "children read more when they listen to stories and discuss stories" (p. 97). Other factors which may have reduced the summer reading slide included the 


\section{This project has also confirmed that the development of a community of readers, in which reading is a base of social interaction, such as the cohort-wide read-aloud, fosters student engagement and discussion about books which can impact positively on student achievement.}

additional support provided to students with Englishlanguage learning needs and the responsiveness to the students' and families' voices in planning for the SRP.

There were particular benefits nonetheless specifically from the 4 weeks in a library over summer. For example, students' responses on a standardised assessment tool (NEMP) suggest increased self-efficacy which were affirmed at the follow-up discussions in which students were strongly positive about their experiences. This may be due to three key factors: first, the research-support teacher knew the students well; secondly, students enjoyed being in the library environment and learning about using a library effectively from a knowledgeable librarian; and thirdly, students developed a sense of ownership of the programme having suggested many of the activities and having an involvement in planning for it throughout the preceding year.

Furthermore we learnt that a partnership with a local public library has the potential to raise student and family awareness of the library as a community resource, as well as helping students to use a library more effectively to maintain reading engagement during the year and over long holiday periods. Such partnerships, however, are challenging to maintain. They require time, and commitment by all parties to establish and review regularly, the mutual expectations of the relationships. What we learnt was that clear communication and continuity of the personnel involved are essential during the planning, preparation, and implementation of a collaboration between a school, the students' whānau, and a local library.

A big question is whether such outcomes are sustainable, given that this group is unlikely to participate in another SRP. Will the summer slide continue to lessen with this cohort? Will the changes in teacher practice continue to impact on motivation, vocabulary acquisition, and comprehension? Assessment data for the research cohort at end of 2015, gathered as part of the school's regular assessment programme, demonstrate that reading achievement gains had been maintained. These data provide an indication of sustainability through to the end of their time at our school and hopefully beyond. There was a lack of difference between the achievement outcomes for the whole cohort and for students who participated in the summer 4-week programme suggests that the impact of the SRP generalised across the cohort. It would appear, however, that this is due to a change in teachers' pedagogy, from which all students benefited, rather than specifically the SRP during the summer holiday.

The emphasis on a shared community of practice focused on children's literature has contributed, we believe, to an improvement in (or at least maintenance of) student reading achievement over the long summer break. What teachers do on a day-to-day basis to foster students' engagement in reading is as critical, if not more critical, than what happens in a holiday reading programme. We also believe developing communities of readers, enhanced and expanded through a strong relationship with a local public library, can reduce the summer reading effect.

This project, we argue, provides further evidence that a summer slide in reading is neither immutable nor inevitable.

\section{Acknowledgements}

We thank the project's reference group for their input and guidance and the Papatoetoe library staff for their willingness to engage with us. We thank Marie Cameron, our critical friend, for her input and advice throughout the project. We also thank the Teaching and Learning Research Initiative (TLRI) for funding the project and Sue McDowall, our TLRI monitor, for her feedback and comment.

\section{Note}

I The New Zealand school year concludes in December with a summer break of around 6 weeks.

2 The qualitative data, including from semistructured interviews and focus groups, were collected using audiorecorders and transcribed to look for themes and patterns in the responses.

\section{References}

Alexander, K. L., Entwisle, D. R., \& Olson, L. S., (2007). Lasting consequences of the summer learning gap. American Sociological Review, 72(4), 167-180. https://doi. org/10.1177/000312240707200202 
Allington, R.L., \& McGill-Franzen, A. (2010). Eliminating summer reading setback: How we can close the rich/poor reading achievement gap. Reading Today, April-May, 10-11.

Anderson, R.C., Hiebert, E.H., Scott, J.A., \& Wilkinson, I.A.G. (1985). Becoming a nation of readers: The report of the Commission on Reading. Washington DC: The National Institute of Education, U.S. Department of Education.

Creswell, J.W. (2009) Research design: Qualitative, quantitative and mixed methods approaches. Thousand Oaks, CA: Sage.

Crooks, T., \& Flockton, L. (2004). Reading and speaking: Assessment results 2004. Retrieved from http://nemp.otago. ac.nz/PDFs/collated_PDFs/NEMP_34_Read_Speak_2004. pdf

Crooks, T., Smith, J., \& Flockton, L. (2008). Reading and speaking: Assessment results 2008. Retrieved from http:// nemp.otago.ac.nz/PDFs/collated_PDFs/NEMP_49_Read_ Speak_2008.pdf

Cunningham, A.E., \& Stanovich, K.E. (1991). Tracking the unique effects of print exposure in children: associations with vocabulary, general knowledge and spelling. Journal of Educational Psychology, 83, 264-274. https://doi. org/10.1037/0022-0663.83.2.264

Elley, W., (2003). STAR (Supplementary Tests of Achievement in Reading). Wellington: New Zealand Council for Educational Research.

Flockton, L., \& Crooks, T. (2000). Reading and speaking: Assessment results 2000. Retrieved from http://nemp. otago.ac.nz/PDFs/collated_PDFs/NEMP_19_Reading _ Speaking_2000.pdf

Kim, J.S., \& Quinn, D.M. (2013). The effects of summer reading on low-income children's literacy achievement from kindergarten to grade 8: A meta-analysis of classroom and home interventions. Review of Educational Research, 83, 3, 386-431. https://doi.org/10.3102/0034654313483906
Krashen, S. D. (2004). The power of reading: Insights from the research. (2nd ed.). Portsmouth, NH: Heinemann.

McNaughton, S., Jesson, R. \& Kolose, T. (2012). School achievement: Why summer matters. Retrieved from http:// www.tlri.org.nz/tlri-research/research-completed/schoolsector/school-achievement-why-summer-matters.

Meyer F., Meissel, K., \& McNaughton, S. (2015). Patterns of literacy learning in German primary schools over the summer and the influence of home literacy practices. Journal of Research in Reading. https://doi.org/10.1111/1467-9817.12061

Rog, L. J. (2001). Early literacy instruction in kindergarten. Newark, DE: International Reading Association.

Turner, L. \& Tse, L.(2015) Solving summer slide: Strategies and suggestions. Set: Research Information for Teachers, (1), 16-24.

Rachel Cromie is the team leader of the cohort of students involved in the project.

Email: rachelc@pcs.school.nz

Ingrid Gwilliam Fa'alogo is the researchsupport teacher.

Email:ingridf@pcs.school.nz

Marilyn Gwilliam is the principal of

Papatoetoe Central School.

Email: marilyng@pcs.school.nz

Dr Libby Limbrick is a researcher at The University of Auckland.

Email:1.limbrick@auckland.ac.nz 